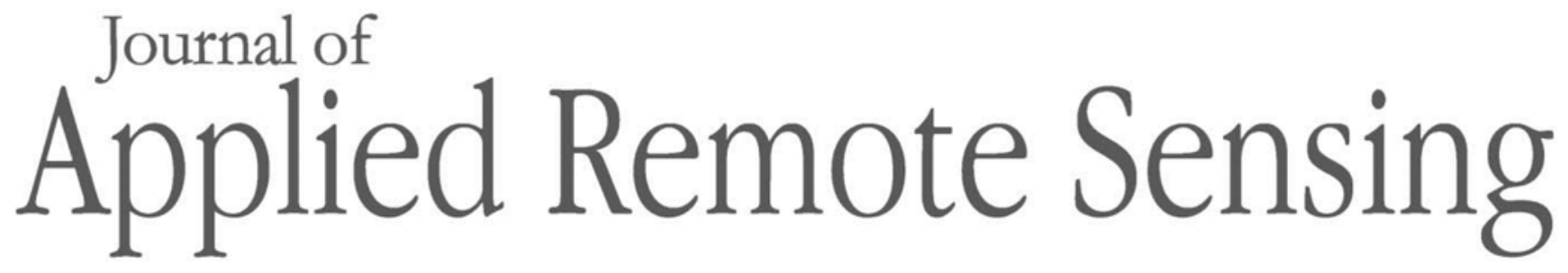

RemoteSensing.SPIEDigitalLibrary.org

\title{
Robust machine learning techniques for rice crop variables estimation using multiangular bistatic scattering coefficients
}

Dileep Kumar Gupta

Rajendra Prasad

Pradeep Kumar

Prashant K. Srivastava

Tanvir Islam

Dileep Kumar Gupta, Rajendra Prasad, Pradeep Kumar, Prashant K. Srivastava, Tanvir Islam, "Robust 


\title{
Robust machine learning techniques for rice crop variables estimation using multiangular bistatic scattering coefficients
}

\author{
Dileep Kumar Gupta, ${ }^{\text {a,b }}$ Rajendra Prasad, ${ }^{\text {a,* }}$ Pradeep Kumar, ${ }^{\text {a }}$ \\ Prashant K. Srivastava, ${ }^{b}$ and Tanvir Islam ${ }^{c, d}$ \\ ${ }^{a}$ Indian Institute of Technology (B.H.U.), Department of Physics, Varanasi, India \\ ${ }^{b}$ Banaras Hindu University, Institute of Environmental and Sustainable Development, \\ Varanasi, India \\ ${ }^{c}$ NASA Jet Propulsion Laboratory, Pasadena, California, United States \\ ${ }^{\mathrm{d}}$ California Institute of Technology, Pasadena, California, United States
}

\begin{abstract}
The present study is designed to explore the potential of bistatic scattering coefficients $\left(\sigma^{\circ}\right)$ and machine learning algorithms for the estimation of rice crop variables using groundbased multiangular, multitemporal, and dual-polarized bistatic scatterometer data. The bistatic scatterometer measurements are carried out at eight different growth stages of the rice crop in the angular range of incidence angle $20 \mathrm{deg}$ to $70 \mathrm{deg}$ for $\mathrm{HH}-$ and VV-polarization at $10-\mathrm{GHz}$ frequency in the specular direction with an azimuthal angle $(\varphi=0)$. Several field measurements are taken for the measurement of rice crop variables, such as vegetation water content, leaf area index, and plant height at its various growth stages. Machine learning algorithms—such as fuzzy inference system (FIS), support vector machine for regression (SVR), and generalized linear model (GLM) - are used to estimate the rice crop variables using bistatic scatterometer data. The linear regression analysis is carried out for the evaluation of the multiangular, multitemporal, and dual-polarized datasets for the selection of optimum incidence angle and polarization for accurate estimation of rice crop variables. The highest value of the coefficient of determination $\left(R^{2}\right)$ is found at 30-deg incidence angle for VV-polarization. The sensitivity of copolarized ratio of $\sigma^{\circ}$ with the rice crop variable is also evaluated using linear regression analysis for the estimation of rice crop variables. The highest value of $R^{2}$ is found to be at 35-deg incidence angle between the copolarized ratio of $\sigma^{\circ}$ and rice crop variables. The performance of SVR model is found superior in comparison to the FIS and GLM at VV-polarization and the copolarized ratio of $\sigma^{\circ}$ for the estimation of rice crop variables. However, the copolarized ratio of $\sigma^{\circ}$ is found superior to VV-polarized bistatic scatterometer data for the estimation of rice crop variables. (C) 2018 Society of Photo-Optical Instrumentation Engineers (SPIE) [DOI: 10.1117/1.JRS.12.034004]
\end{abstract}

Keywords: bistatic scatterometer; X-band; rice crop; fuzzy logic; support vector regression.

Paper 180101 received Feb. 6, 2018; accepted for publication Jul. 31, 2018; published online Aug. 20, 2018.

\section{Introduction}

Rice is a staple food for billions of people in the world. The accurate and effective estimation of rice crop growth variables is one of the key steps in effective monitoring of rice crop growth. The microwave remote sensing has a great potential to complement traditional remote sensing techniques for monitoring and assessment of crop growth. ${ }^{1}$ The remote sensing for agricultural applications requires relatively high temporal and spatial resolution data. The microwave sensors may be more effective than optical sensors for the monitoring of rice growth stages in the tropical monsoon climate region of Asia.

*Address all correspondence to: Rajendra Prasad, E-mail: rprasad.app@itbhu.ac.in

$1931-3195 / 2018 / \$ 25.00$ (C) 2018 SPIE 
Several researchers have conducted experiments to investigate the microwave response of rice crops at different radar configuration of space-borne ${ }^{2-5}$ and ground-based ${ }^{1,6-10}$ microwave $^{-1}$ sensors. SooBum et al. ${ }^{11}$ have carried out ground-based monostatic measurements over the whole period of rice crop growth at X-band with $\mathrm{HH}-, \mathrm{VV}-$, and $\mathrm{HV}$-polarizations in the incidence angle range of $0 \mathrm{deg}$ to $70 \mathrm{deg}$. Oh et al. ${ }^{7}$ reported the ground-based polarimetric (HH-, VV-, HV-, and $\mathrm{VH}-$ ) scatterometer measurements during the rice crop growth cycle from transplanting period to harvest period at C- and L-band for different incidence angles (i.e., $30 \mathrm{deg}$, $40 \mathrm{deg}, 50 \mathrm{deg}$, and $60 \mathrm{deg}$ ). Inoue et al. ${ }^{6}$ used a multifrequency polarimetric scatterometer system to investigate the interaction between microwave backscattering and rice crop growth variables using five different frequencies $(\mathrm{Ka}, \mathrm{Ku}, \mathrm{X}, \mathrm{C}$, and $\mathrm{L}$ ) with all the polarizations (HH-, VH-, HV-, and VV-) and four incident angles (25 deg, $35 \mathrm{deg}, 45 \mathrm{deg}$, and $55 \mathrm{deg}$ ) for the entire growth period of the rice crop. The correlation between backscattering coefficients and crop variables was also analyzed. The leaf area index (LAI) was found best correlated with the backscattering coefficient at HH- and cross-polarization for C-band. However, the fresh biomass was found best correlated with backscattering coefficient at $\mathrm{HH}$ - and cross-polarization for L-band.

Most of the previous researchers have used monostatic radar geometry to monitor the rice growing areas and estimation of the rice crop variables. In the case of bistatic radar, the transmitter and receiver are placed opposite to each other in different azimuthal configurations, whereas the transmitter and receiver are placed at the same location in monostatic radar measurements. The bistatic scattering coefficient can provide multidimensional information of land features due to the diversity of geometry available to the transmitting and receiving antennas. The bistatic scattering coefficient is more sensitive to the vegetation parameters than the backscattering coefficients. The bistatic scattering coefficients do not exhibit severe saturation effects at the maturity of the crops and show a better sensitivity to crop growth variables at its various growth stages than the backscattering coefficient. ${ }^{12}$

Until now, very few researchers have used bistatic radar geometry for the retrieval of rice crop variables. Recently, German Aerospace Centre (DLR) and EADS Astrium have launched a mission for bistatic radar system with twin satellites (TerraSAR- X and TanDEM-X). Erten et al. ${ }^{13}$ showed that the TanDEM-X mission is capable of tracking the plant growth of rice crop. They compared the performance of vertical and horizontal polarizations of TanDEM-X for the temporal mapping of rice crop height. The difference in height was found $10 \mathrm{~cm}$ between the rice plant height $(\mathrm{PH})$ measurements in the HH- and VV-channels of TanDEM-X at reproductive stage. Rossi and Erten ${ }^{14}$ have evaluated the potential of space-borne bistatic interferometric synthetic aperture radar images for the monitoring of biophysical variables of the rice crop. The X-band differential bistatic interferometry radar images showed great benefit in elevation mapping of $\mathrm{PH}$ of rice crop by 32 digital elevation models. Therefore, it is needed to explore the potential of bistatic radar for monitoring the growth stages of crop/vegetation.

Currently, the machine learning algorithms (i.e., artificial neural network, fuzzy logic, support vector machine for regression and genetic algorithm, etc.) are widely used to analyze the radar data for many agricultural applications. These machine learning algorithms may have advantages over the semiempirical or physical models for the estimation of rice crop growth variables using radar data. Yang et al. ${ }^{15}$ overcame the difficulties in the selection of the optimum values of fuzzy logic parameters based on self-learning system. They found that the simulation is stronger in robustness and higher in control accuracy. They also found the system performance to be greatly enhanced. Lin et al. ${ }^{16}$ describe the particle swarm optimization (PSO) based approach to select the optimum values of SVM parameters. They found better classification accuracy using developed PSO + SVM approach in comparison to other approaches. Huang and Wang ${ }^{17}$ have used genetic algorithm (GA) based approach to optimize the parameters and feature selection of datasets for SVM. They evaluated the GA-based SVM classification accuracy with RBF kernel and the grid algorithm using real-world datasets. Several researchers have developed robust machine learning algorithms by selecting the appropriate model parameters using error-trial methods, which provided the encouraging results. ${ }^{18-20}$ Frate et al. ${ }^{21}$ have trained two separate artificial neural networks algorithms by physical vegetation model to retrieve the soil moisture and wheat crop variables using L-band, dual-polarized, and multiangular radiometric data. They found the retrieval process quite effective. Champs-Valls et al. ${ }^{22}$ have introduced the $\varepsilon$-Huber loss function in the support vector regression (SVR) algorithms for the estimation of biophysical 
parameters using remotely sensed data. Their proposed model has provided more accurate, less biased, and improved robust estimation results. Pandey et al. ${ }^{23}$ used the fuzzy inference system (FIS) algorithms and scatterometer data for the estimation of crop variables. They found that the estimated values were very close to the observed values of the crop variables. Jia et al. ${ }^{24}$ have evaluated the potential of the artificial neural network for the estimation of rice crop biomass using quad polarized ground-based scatterometer data and RADARSAT- 2 data. They found high correlation coefficients between measured rice crop biomass and estimated rice crop biomass for both the datasets.

The objective of this research is focused on the application of two machine learning algorithms (FIS and SVR) along with GLM to estimate the rice crop variables using multitemporal, dual-polarized (HH- and VV-), and multiangular datasets acquired by ground-based bistatic scatterometer system at X-band. The copolarization ratio of $\sigma^{\circ}$ is also evaluated for the estimation of rice crop variables. This paper has the following structure. In Sec. 2, we have discussed the experimental set-up and measurements technique. Section 3 includes the details of various machine learning algorithms along with GLM and their optimization method and evaluation of datasets. Section 4 covers results and discussions. Section 5 contains the conclusions of the present work.

\section{Methods}

An experimental campaign carried out by the bistatic scatterometer system along with rice growth variables measurements is performed over the uniform rice crop field from August 13, 2012 to November 21, 2012. The angular response of bistatic scattering coefficients is analyzed over the rice growing season at X-band for HH- and VV-polarization. The multitemporal, multiangular, and dual-polarized bistatic scatterometer data are also evaluated for the estimation of rice crop variables.

\subsection{Bistatic Scatterometer Measurement}

The technical specifications and real photograph of bistatic scatterometer set-up are presented in Table 1 and Fig. 1(a), respectively. Figure 1(b) shows the geometry of the bistatic scatterometer system used in the present study. In the bistatic configuration, the transmitter and receiver are placed on opposite side to each other during measurements made for microwave signature study of rice crop at its various growth stages. The transmitter consists of PSG high power signal generator $(\mathrm{E} 8257 \mathrm{D}, 10 \mathrm{MHz}$ to $20 \mathrm{GHz}), \mathrm{X}$-band pyramidal dual polarized horn antenna, and antenna support tower. The receiver consists of EPM-P series power meter (E4416A), peak and average power sensor (E9327A, $50 \mathrm{MHz}$ to $18 \mathrm{GHz}$ ), pyramidal dual polarized horn antenna, and antenna support tower. The polarization of the horn antenna is changed by using $90 \mathrm{deg}$ E-H twister. The antenna support towers have the capability to change incidence angle and height of transmitting and receiving antennas. The incidence angle and height of transmitting and receiving antennas are measured by a pointer attached with the circular scale and linear scale, respectively. The laser pointer is used to focus transmitting and receiving antenna beams at the center of rice crop bed. The laser pointer helps to overlap the footprint of both (transmitting and receiving) antennas at the center of the rice crop bed.

The bistatic measurements are carried out at $\mathrm{HH}$ - and VV- polarization in the incidence angle range of $20 \mathrm{deg}$ to $70 \mathrm{deg}$ at steps of $5 \mathrm{deg}$. Three independent measurements are taken at each incidence angles for azimuthal angle $\varphi=0$ in the specular direction during the whole life cycle of rice growth.

The internal calibration of bistatic scatterometer system is done using the power ratio method. ${ }^{25}$ The $\sigma^{\circ}$ of the distributed target is directly proportional to the ratio between received power from the target and transmitted power. All the gain and losses are considered for the measurement of received and transmitted power except antenna gain of the bistatic scatterometer system.

The external calibration of bistatic scatterometer system is done using a flat and conducting aluminum sheet. The amplitudes of the scattered signal from the scatter (rice crop) and reflected 
Gupta et al.: Robust machine learning techniques for rice crop variables estimation...

Table 1 Specification of bistatic scatterometer system.

\begin{tabular}{|c|c|}
\hline RF generator & $\begin{array}{l}\text { E8257D, PSG high power signal generator, } \\
10 \mathrm{MHz} \text { to } 20 \mathrm{GHz} \text { (Agilent Technologies) }\end{array}$ \\
\hline Power meter & $\begin{array}{l}\text { E4416A, EPM-P series power meter, } \\
10 \mathrm{MHz} \text { to } 20 \mathrm{GHz} \text { (Agilent Technologies) }\end{array}$ \\
\hline Power sensor & $\begin{array}{l}\text { Peak and average power sensor (E9327A, } \\
50 \mathrm{MHz} \text { to } 18 \mathrm{GHz} \text { ) }\end{array}$ \\
\hline Frequency $(\mathrm{GHz})$ & $10 \pm 0.05(X-b a n d)$ \\
\hline \multirow[t]{2}{*}{ Beam width } & 17.31 \\
\hline & 19.59 \\
\hline Band width $(\mathrm{GHz})$ & 0.80 \\
\hline Antenna gain $(\mathrm{dB})$ & 20.00 \\
\hline Cross-polarization isolation $(\mathrm{dB})$ & 40.00 \\
\hline \multirow[t]{2}{*}{ Polarization modes } & Horizontal transmit - horizontal receive $(\mathrm{HH})$ \\
\hline & Vertical transmit - vertical receive (VV) \\
\hline Antenna type & Dual-polarized pyramidal horn \\
\hline Calibration accuracy $(\mathrm{dB})$ & 1.00 \\
\hline Platform height $(\mathrm{m})$ & 3.00 \\
\hline Incidence angle (deg) & $20 \mathrm{deg}$ (nadir) to $70 \mathrm{deg}$ \\
\hline Measurement interval & $20 \mathrm{~min}$ \\
\hline
\end{tabular}

power from the perfectly smooth and conducting aluminum sheet are observed for the entire angular range. The amplitudes of scattered power from scatter are normalized using the reflected power by the aluminum sheet for the calibration of bistatic scatterometer system. The normalized power is used to compute the $\sigma^{\circ}$ using radar equation. ${ }^{26}$ The antennas are placed in the far-field region from the center of the target to minimize the near-field interactions. The calibration of the system is done regularly during the experiment to ensure the integrity of the system.

\subsection{Study Site and Rice Growth Variables}

An outdoor rice crop bed of area $4 \mathrm{~m} \times 4 \mathrm{~m}\left(16 \mathrm{~m}^{2}\right)$ is specially prepared for the transplanting of the rice crop. The crop bed is flooded with water before transplanting the rice crop. The rice crop bed is located in the study site besides the Department of Physics, Indian Institute of Technology (BHU), Varanasi, India (latitude $25^{\circ} 13^{\prime} 52^{\prime \prime} \mathrm{N}$ and longitude $82^{\circ} 38^{\prime} 41^{\prime \prime} \mathrm{E}$ ). The rice seeds were sown in the nursery on July 10, 2012. After 1 month, the rice plants are uniformly transplanted in the crop bed. The distance between each row of rice plants is kept $20 \mathrm{~cm}$. The whole life cycle of the rice crop is divided into its different phenological stages to understand the temporal microwave scattering response of the rice crop growth variables at various growth stages. The entire growth period of the rice crop can be divided into three major growth stages after transplanting, such as (1) the vegetative stage, starting from effective tillering (August 13) and ending with panicle formation (September 22); (2) the reproductive stage, it starts from panicle formation (September 22) to heading (October 22); and (3) the ripening or maturating stage, it starts from heading through soft dough (October 22) and ends with the formation of hard grains (November 21).

The bistatic measurements are carried out at eight different growth stages of rice crop $(5,18$, $30,45,60,75,85$, and 105 days after transplanting) at the interval of 10 to 15 days from transplanting to ripening stage. The measurement of rice crop variables is carried out at the time of each bistatic scatterometer measurement, as reported in Table 2. 


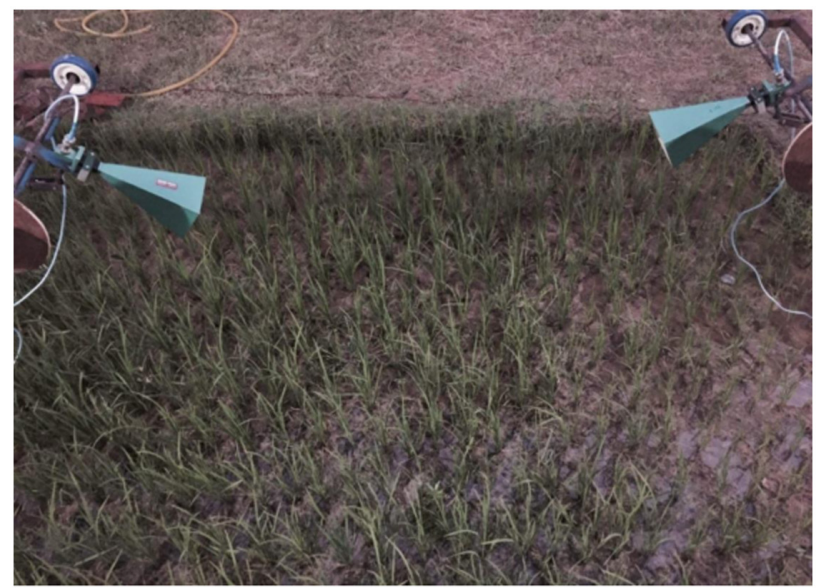

(a)

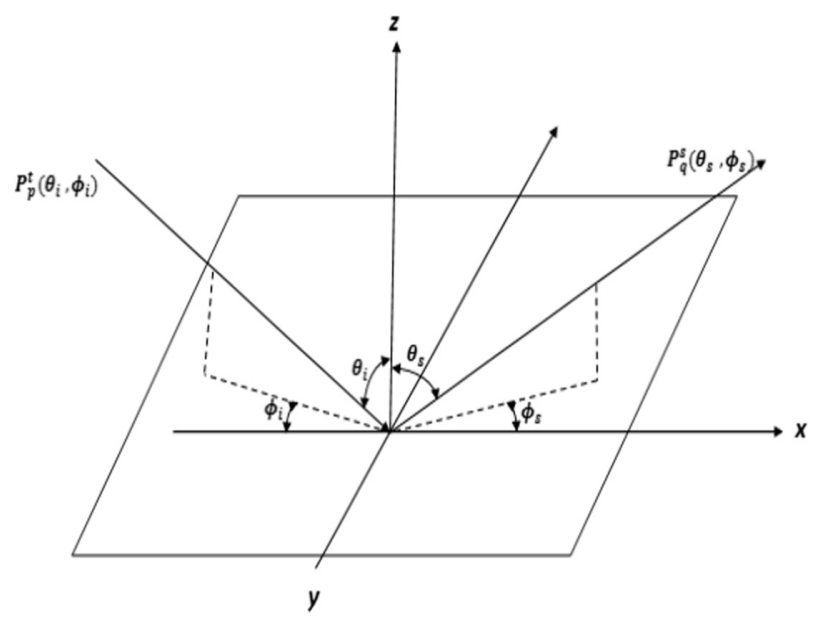

(b)

Fig. 1 Pictorial representation of bistatic scatterometer system: (a) real photograph of bistatic scatterometer system and (b) geometrical representation of bistatic scatterometer system.

Table 2 Measurement in days after transplanting and summary of the ground truth data.

\begin{tabular}{lcccccccc}
\hline \hline Days after showing & 5 & 18 & 30 & 45 & 60 & 75 & 85 & 105 \\
\hline VWC $\left(\mathrm{kgm}^{-2}\right)$ & 0.09 & 0.45 & 0.80 & 1.24 & 1.69 & 2.40 & 2.57 & 2.42 \\
LAI $\left(\mathrm{m}^{2} \cdot \mathrm{m}^{-2}\right)$ & 0.32 & 1.25 & 1.27 & 1.39 & 1.87 & 1.92 & 2.12 & 1.98 \\
PH $(\mathrm{cm})$ & 10.80 & 24.80 & 65.60 & 79.00 & 90.00 & 101.00 & 105.00 & 102.00 \\
Stems per bunch & 6.00 & 9.00 & 11.00 & 12.00 & 15.00 & 17.00 & 18.00 & 18.00 \\
No. of leaves per stem & 2.00 & 2.00 & 3.00 & 3.00 & 3.00 & 4.00 & 4.00 & 4.00 \\
Bunches $/ \mathrm{m}^{2}$ & 42.00 & 42.00 & 42.00 & 42.00 & 42.00 & 42.00 & 42.00 & 42.00 \\
Leaf length (cm) & 7.45 & 14.82 & 18.66 & 26.42 & 31.92 & 34.74 & 35.47 & 36.21 \\
Leaf width $(\mathrm{cm})$ & 0.16 & 0.45 & 0.50 & 0.80 & 0.99 & 1.10 & 1.20 & 1.34 \\
Leaf thickness $(\mathrm{mm})$ & 0.19 & 0.19 & 0.19 & 0.19 & 0.20 & 0.21 & 0.24 & 0.30 \\
\hline \hline
\end{tabular}


The rice crop variables like vegetation water content (VWC), LAI, PH, plant density, number of stems per bunches, leaf length, leaf width, etc., are measured during each observation. The VWC is defined as the total water content available in the plant constituents in $1-\mathrm{m}^{2}$ area. The total number of rice clusters at the crop bed is calculated and divided by 16 for the calculation of a number of rice clusters per $\mathrm{m}^{2}$ (cluster density). The VWC is computed by using the destructive method of rice clusters. Five rice clusters are taken from the different locations of the crop bed during each observation. These five samples are selected from the outer edge of the crop bed so that the crop lying in the footprint area of the antenna beam on the crop bed remains unaffected. These five samples of rice clusters contain all type of rice clusters available in the crop bed. The leaves and stalks of rice clusters (five samples) were dried in an oven at $100^{\circ} \mathrm{C}$ for $24 \mathrm{~h}$. These five samples were weighed before and after drying. The average of all five samples was taken to compute the overall VWC. The VWC can be computed as follows:

$\mathrm{VWC}=($ weight of fresh rice cluster - weight of dry rice cluster $) \times$ cluster density.

An instrument ACCUPAR LP-80 Ceptometer ${ }^{27-29}$ is used for the measurement of LAI of the rice crop. The 20 samples of LAI are taken at different locations and at different sun ray directions on the rice crop bed. This instrument has a linear probe containing 80 light interception sensors. The instrument can measure photosynthetically active radiation (PAR) and LAI. It measures the LAI by measuring the PAR above and below the canopy. The five measurements of LAI are taken at each side of the crop bed (four sides of the crop bed along east, west, north, and south directions). The average of all 20 LAI samples is taken to compute the overall LAI. The sun rays direction, sunlight intensity, and alignment of the sensors are the important parameters for the accurate measurement of LAI by ACCUPAR LP-80 Ceptometer instrument. We have taken the measurements at all the four sides of the crop bed to avoid the error due to the direction of sun rays. The bubble provided on the top of the probe should be kept at the center to minimize the error in the alignment of the probe. The LAI measurements are taken during sufficient sunlight required for accurate measurement.

A linear wooden scale of 2-m length is used to measure the PH in the crop bed under the investigation. The wooden scale is kept vertically in the crop bed. Another thick wooden sheet $(5 \mathrm{~mm})$ placed over the plants touched with the top edge of the plants. The thick wooden sheet marks a point on the vertically linear scale and reads the average height of plants. A Vernier caliper is used to measure the width and thickness of leaves of the rice crop. The linear scale is used to measure the leaf length of the rice plants. The measurement of leaf length is simple but width measurement is very tedious due to its shape. The leaf length was measured from bottom to top tip of the leaf. The major size along the width of the leaf is considered as the leaf width.

\subsection{Evaluation of Datasets for the Estimation of Rice Crop Variables}

The linear regression analysis is carried out between $\sigma^{\circ}$ and rice crop variables to evaluate the higher sensitivity of $\sigma^{\circ}$ with the rice crop variable from multitemporal, multiangular, and dualpolarized bistatic scatterometer data. The higher value of $R^{2}$ tells the higher sensitivity between $\sigma^{\circ}$ and rice crop variables. The value of $R^{2}$ is found to be higher at 30-deg incidence angle for all the rice crop variables with the $\sigma^{\circ}$ at $\mathrm{HH}$ - and VV-polarization. Figures 2 and 3 show matrix correlation plot, which are drawn to evaluate the sensitivity of the $\sigma^{\circ}$ with all the rice crop variables individually for 30-deg incidence angle at $\mathrm{HH}$ - and VV-polarization, respectively. In the case of copolarization ratio of $\sigma^{\circ}$, the value of $R^{2}$ is found to be higher at 35-deg incidence angle. Figure 4 is drawn to evaluate the sensitivity of copolarization ratio of $\sigma^{\circ}$ with all the rice crop variables individually at 35-deg incidence angle. The sensitivity of $\sigma^{\circ}$ with the crop variables is found to be higher at $30 \mathrm{deg}$ and $35 \mathrm{deg}$ in the case of both like polarization and copolarized ratio, respectively. Thus, bistatic scatterometer system may be set at around $30 \mathrm{deg}$ to $35 \mathrm{deg}$ for the accurate estimation of crop variables.

The HH- and VV-polarized $\sigma^{\circ}$ are found more sensitive to the rice VWC than the other rice crop variables at its various growth stages, whereas the VV-polarized $\sigma^{\circ}$ is found more sensitive for rice $\mathrm{LAI}$ and $\mathrm{PH}$ at various growth stages of rice crop than $\mathrm{HH}$-polarized $\sigma^{\circ}$. The polarization 
Gupta et al.: Robust machine learning techniques for rice crop variables estimation...

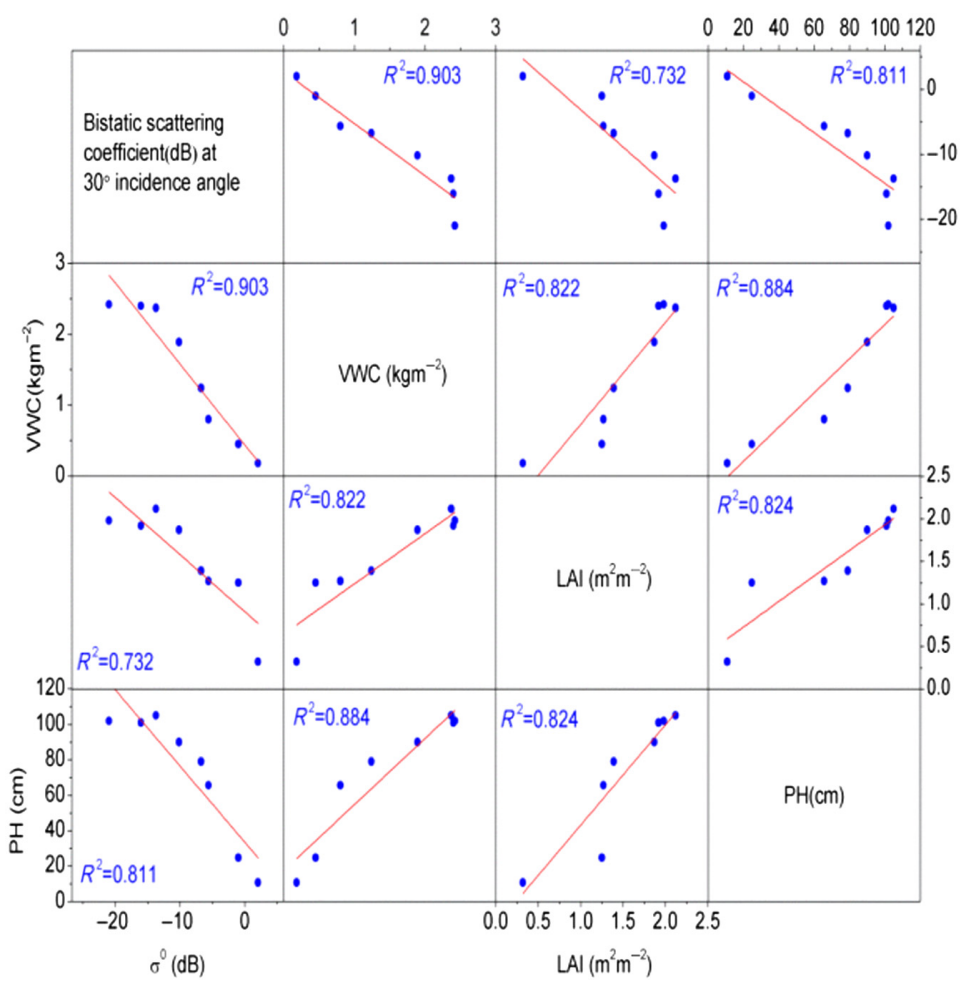

Fig. 2 Correlation matrix plot between bistatic scattering coefficients and rice crop variables at $\mathrm{HH}$-polarization.

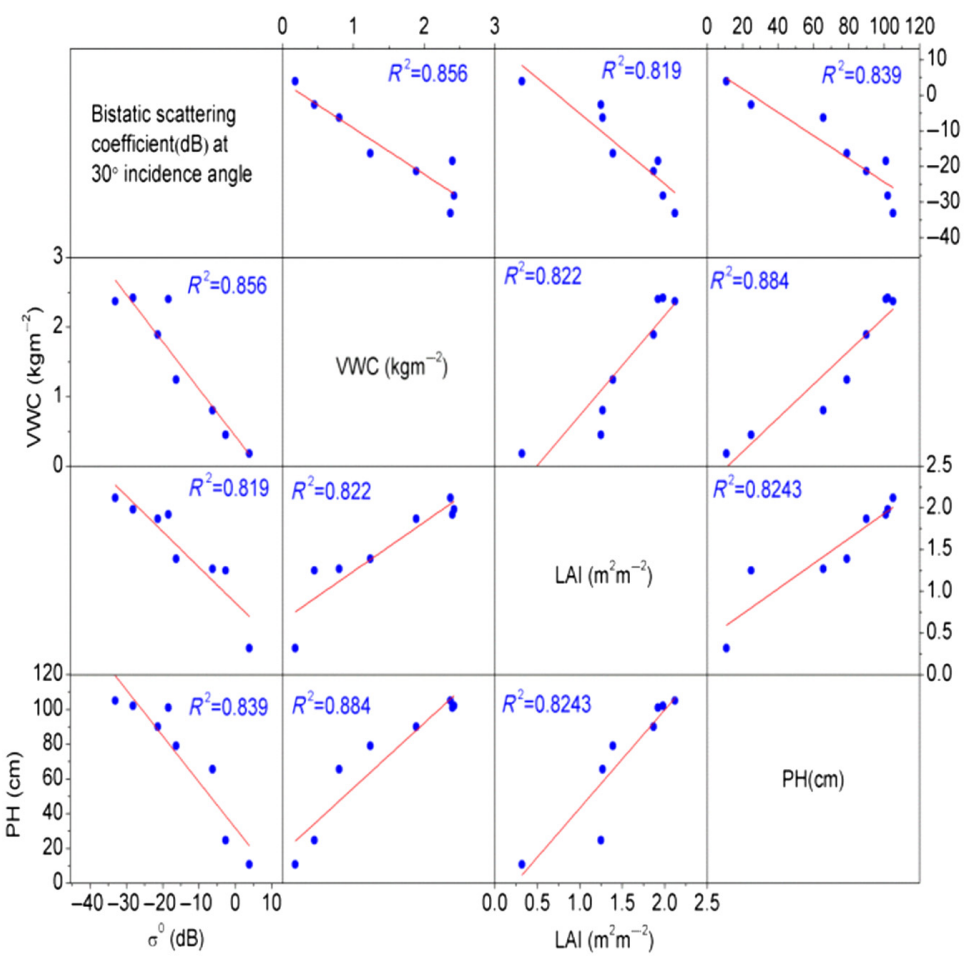

Fig. 3 Correlation matrix plot between bistatic scattering coefficients and rice crop variables at VV-polarization. 


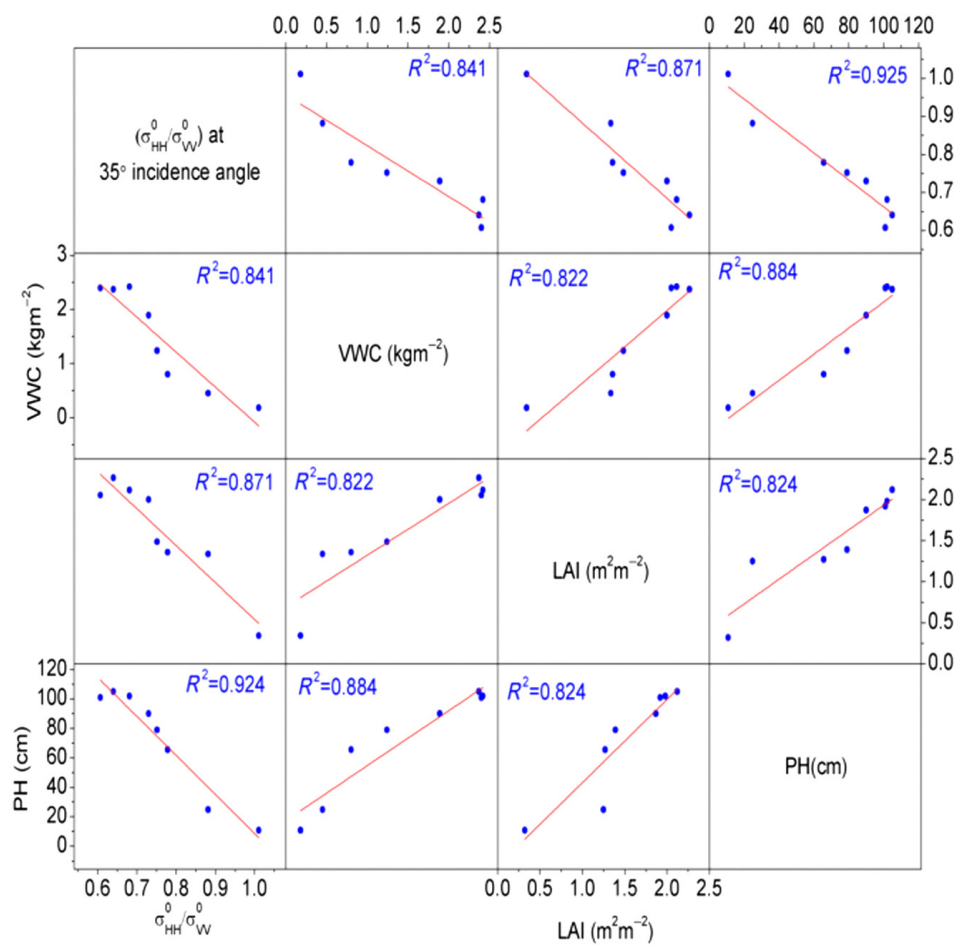

Fig. 4 Correlation matrix plot between copolarization ratio of $\sigma^{\circ}$ and rice crop variables.

of a microwave is sensitive to the shape, size, and orientation of the target elements. The horizontal polarization gives the measure of the horizontal dimension of the scattering elements, while the vertical polarization gives a measure of the vertical dimension. The VV-polarized $\sigma^{\circ}$ contribution is found more dominant than the $\mathrm{HH}$ - polarized $\sigma^{\circ}$ due to the interaction with the vertically oriented leaves and stems of the rice crop. Most of the rice crop constituents, namely leaves and stems are vertically oriented. The total water content available in the rice crop constituents is described by VWC of the rice crop. The change in water content in the plant constituents at various growth stages of the rice crop is responsible for the changes in electrical properties (dielectric constant) of the rice crop at microwave frequencies. The change in LAI and $\mathrm{PH}$ of rice at its various growth stages is responsible for the changes in geometrical properties of rice crop for the microwave. The copolarization ratio of $\sigma^{\circ}$ has shown higher sensitivity for all the rice crop variables than $\mathrm{HH}$ - and $\mathrm{VV}$-polarized $\sigma^{\circ}$.

The sensitivities between each rice variable are found to be approximately similar at various growth stages of the rice crop. It means that the changes in each rice crop variables have shown significant correlation with other rice crop variables during the entire crop development. The value of $R^{2}$ is found slightly higher at HH-polarization just by 0.047 than the corresponding value at VV-polarization for rice VWC. This difference of $R^{2}$ does not indicate the significantly higher sensitivity at HH-polarization than VV-polarization. The VV-polarized $\sigma^{\circ}$ may be the best choice for the estimation of rice crop variables. Sensitivity of the copolarization ratio of $\sigma^{\circ}$ with the rice crop variables is also investigated to determine the possibility of using a copolarization ratio of $\sigma^{\circ}$ for the estimation of rice crop variables.

The VV-polarized $\sigma^{\circ}$ and the copolarization ratio of $\sigma^{\circ}$ are used as the input datasets while the rice crop variables namely VWC, LAI, and $\mathrm{PH}$ are used as the output datasets for the training and testing of machine learning algorithms. In the present study, the data acquisition is carried out at eight different growth stages of the rice crop. The large datasets are required for the proper training of the machine learning algorithms. The $\sigma^{\circ}$ and rice crop variables are interpolated into 101 datasets at the interval of 1 day from 5 to 105 days after transplanting of rice crop at 30-deg incidence angle for VV-polarization. The cubic spline interpolation method is used to perform the interpolation of datasets. The interpolated datasets for the various growth stages of rice crop are used for the training and testing of machine learning algorithms. Eighty one datasets (at 6-9, 
11-14, 16-19, 21-24, 26-29, 31-34, 36-39, 41-44, 46-49, 51-54, 56-59, 61-64, 66-69, 71-74, $76-79,81-84,86-89,91-94,96-99$, and 105 days after transplanting) out of 101 datasets are selected for the training while the remaining 20 datasets (at 5,10, 15, 20, 25, 30, 35, 40, 45, $50,55,60,65,70,75,80,85,90,95$, and 100 days after transplanting) are kept separately for the testing purposes of machine learning algorithms.

The six different combinations of datasets are used for the training and testing of machine learning algorithms. The inputs and outputs of these datasets are (i) input: VV-polarized $\sigma^{\circ}$ and output: rice VWC; (ii) input: VV-polarized $\sigma^{\circ}$ and output: rice LAI; (iii) input: VV-polarized $\sigma^{\circ}$ and output: rice $\mathrm{PH}$; (iv) input: copolarized ratio of $\sigma^{\circ}$ and output: rice VWC; (v) input: copolarized ratio of $\sigma^{\circ}$ and output: rice LAI; and (vi) input: copolarized ratio of $\sigma^{\circ}$ and output: rice PH. Each dataset is used separately for training and testing of machine learning algorithms.

\section{Machine Learning Algorithms}

\subsection{Fuzzy Logic}

Fuzzy logic is a mathematical approach dealing with membership functions (MFs), fuzzy sets, and fuzzy operators to form many sets of rules to establish the suitable relationships between given input and output datasets. These set of rules deal with approximate, rather than fixed and exact reasoning. The fuzzy logic variables may have truth values with ranges in degree between 0 and 1 in comparison to the traditional binary logic (fuzzy logic variables may have only true or false values). The fuzzy logic provides a better understanding of the things present in the world that surrounds us and is defined by a nondistinct boundary based upon vague, ambiguous, imprecise, noisy, and missing input information. ${ }^{30}$

The membership values of all the inputs generated through MF at fuzzification layer exist in the premise part. This process is called fuzzification of the fuzzy logic. All these membership values of FIS algorithms are combined to the firing strength (weight) by using a fuzzy logic controller. The crisp output is produced by the generation of qualified consequents for each rule depending on the firing strength. This process is called defuzzification of fuzzy logic. ${ }^{31}$ The two steps are necessary to follow the fuzzy logic for any computation, namely data clustering and developing FIS algorithms.

Many supervised and unsupervised data clustering techniques are available to categories and identify the different group of datasets. In the present study, the unsupervised subtractive clustering method ${ }^{32}$ is used for clustering or grouping the same categories of datasets generated from $\sigma^{\circ}$ and rice crop variables. The subtractive clustering method is used to estimate the number of clusters and the cluster centers in a set of data. The subtractive clustering method assumes each data point as a potential cluster center and calculates the likelihood that each data point would define the cluster center based on the density of surrounding data points. First, it considers all the data points with the highest potential to be the first cluster and removes all the data points. The surrounding area of the cluster center is determined by the radii of the clusters. The next data cluster and its central location can be determined by the iterative process of all data within radii of the cluster center.

The FIS algorithm is a Sugeno type fuzzy model having a systematic approach for generating the fuzzy rules from a given input-output dataset. ${ }^{33,34}$ The FIS algorithms generally composed of five layers, such as input layer, MF or fuzzification layer, rule layer, consequent layer, output or defuzzification layer. The first layer contains input nodes. The input nodes directly transmit inputs to the next layer. The mathematical representation at first layer is given by Eq. (2):

$$
O_{i}^{(1)}=x_{i}
$$

The second layer is called as MF or fuzzification layer. At this layer, the membership value specifies the degree to which an input value belongs to a fuzzy set. The Gaussian MF is assumed to calculate the membership values for the input $x_{i}$ : 


$$
O_{i j}^{(2)}=\exp \left\{-\frac{\left[O_{i}^{(1)}-m_{i j}\right]^{2}}{\sigma_{i j}^{2}}\right\}
$$

where $m_{i j}$ and $\sigma_{i j}$ are the mean and standard deviation of the Gaussian MF of the $j$ 'th term of $i$ 'th input variables.

The third layer in the FIS algorithms is called rule layer. In this layer, the output at each node is determined by the AND operation between the outputs of the second layer. The product rule is utilized to determine the firing strength of each rule. The function of each rule is as follows:

$$
O_{j}^{(3)}=\prod_{j} O_{i j}^{(2)} .
$$

The fourth layer is called consequent layer. The inputs to the layer 4 are delivered from the output of layer 3 and other inputs from the input variables of layer 1. Mathematically, the output at the nodes of layer 4 is as follows:

$$
O_{j}^{(4)}=O_{j}^{(3)}\left(w_{o j}+\sum_{i}^{\mathrm{n}} w_{i j} x_{i}\right),
$$

where $w_{i j}$ are the corresponding parameters of the consequent part.

The last layer or output layer or defuzzification layer represented by only one node indicates the overall outputs by performing the summation of all incoming signals as follows:

$$
y=O^{5}=\frac{\sum_{j=1}^{\mathrm{R}} O_{j}^{(4)}}{\sum_{j=1}^{\mathrm{R}} O_{j}^{(3)}}=\frac{\sum_{j=1}^{\mathrm{R}} O_{j}^{(3)}\left(w_{o j}+\sum_{i}^{\mathrm{n}} w_{i j} x_{i}\right)}{\sum_{j=1}^{\mathrm{R}} O_{j}^{(3)}},
$$

where $\mathrm{R}$ is the number of fuzzy rules and $n$ is the number of input variables. ${ }^{35}$

\subsection{Support Vector Regression}

The SVMs for regression are first introduced by Vapnik et al. ${ }^{36}$ The SVR algorithm performs linear regression in the feature space using $\varepsilon$-insensitive loss function. At the same time, it tries to reduce the model complexity by minimizing $\left\|w^{2}\right\|$. The SVR algorithm is mathematically formulated as follows:

$$
\operatorname{Min} \frac{1}{2}\left\|w^{2}\right\|+C \sum_{i=1}^{N}\left(\xi_{i}+\xi_{i}^{*}\right)
$$

subject to

$$
\begin{aligned}
& w^{\mathrm{T}} \phi\left(x_{i}\right)-y_{i} \leq \varepsilon+\xi_{i}, \\
& y_{i}-w^{\mathrm{T}} \phi\left(x_{i}\right) \leq \varepsilon+\xi_{i}^{*},
\end{aligned}
$$

where $\xi_{i}, \xi_{i}^{*} \geq 0, i=1, \ldots, N$ and $\phi$ maps the data point $x$ into high-dimensional feature space and linear regression with $\varepsilon$-insensitive loss function performed is the feature space. Here, $\phi$ is the kernel function, $N$ is the number of training data, $x_{i}$ and $y_{i}$ are vectors used in the training process. As a consequence, the dimension of $w$ is that of $\phi(w)$ and hence, there is no attempt to express the target function in terms of $w .^{32}$ The least squares approach is used to choose the parameters $\left(\xi_{i}, \xi_{i}^{*}\right)$ to minimize the sum of the squared deviations of the data.

\subsection{Generalized Linear Model}

In statistical models, the GLM relates the responses to linear combinations of predictor variables, including many commonly encountered types of dependent variables and error structures as special cases. ${ }^{37,38}$ One variable is considered to be an independent variable $x_{i}$, and the other is considered to be a dependent variable $y_{i} .{ }^{39}$ They are represented as follows:

$$
y_{i}=x_{i} b+e_{i}
$$


where $i=1, \ldots, n ; y_{i}$ is a dependent variable, $x_{i}$ is the independent predictors, $b$ is a vector of unknown parameters, and $e_{i}$ is stochastic disturbances. GLM models are characterized by stochastic component, systematic component, and link between the random and systematic components. ${ }^{40}$

\subsection{Description and Optimization of Machine Learning Parameters}

The FIS algorithm is realized by formulating the data clustering for the estimation of rice crop variables using bistatic scatterometer data. The subtractive clustering algorithm is used for

Table 3 Optimum parameters for fuzzy logic during data clustering and generation of FIS.

\begin{tabular}{lcccc}
\hline \hline Rice crop variable & No. of clusters & No. of fuzzy rules & Radii value & Polarization \\
\hline VWC & 4.00 & 4.00 & 0.10 & $\mathrm{VV}$ \\
$\mathrm{LAl}$ & 3.00 & 3.00 & 0.10 & $\mathrm{VV}$ \\
$\mathrm{PH}$ & 6.00 & 6.00 & 0.20 & $\mathrm{VV}$ \\
VWC & 3.00 & 3.00 & 0.10 & $\mathrm{HH} / \mathrm{VV}$ \\
$\mathrm{LAI}$ & 3.00 & 3.00 & 0.10 & $\mathrm{HH} / \mathrm{VV}$ \\
$\mathrm{PH}$ & 4.00 & 4.00 & 0.20 & $\mathrm{HH} / \mathrm{VV}$ \\
\hline \hline
\end{tabular}
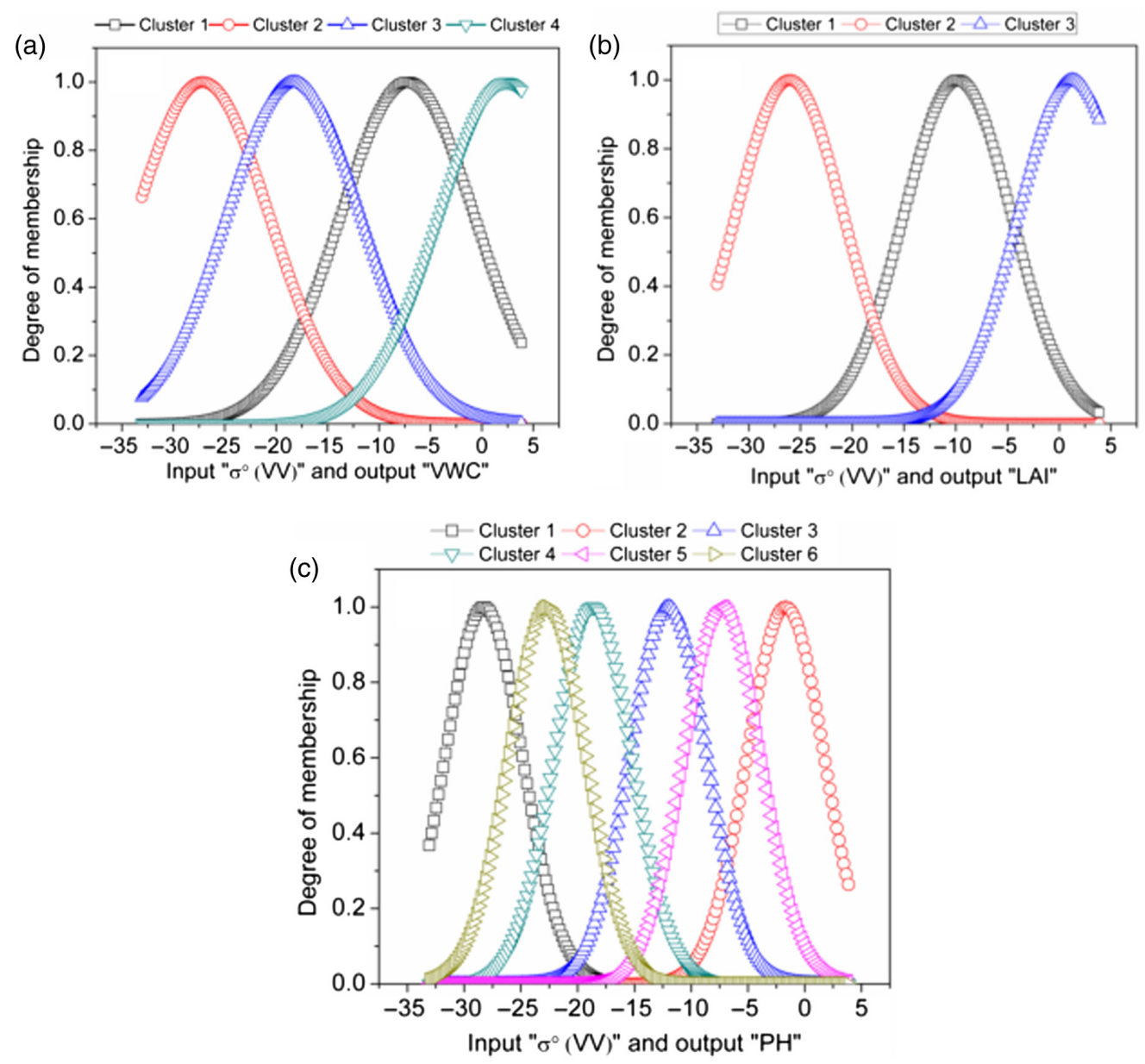

Fig. 5 MF plot at HH-polarization for (a) VWC, (b) LAI, and (c) PH. 
the clustering of six different datasets to generate the fuzzy rules for FIS algorithm between $\sigma^{\circ}$ and rice crop variables. Table 3 depicts the optimum values of FIS parameters (radii values, number of clusters, and number of fuzzy rules) obtained for all six datasets (described in Sec. 2.3). The Sugeno or Takagi-Sugeno-Kang type FIS algorithm is used to generate a fuzzy inference system to predict the desired output. The optimum value of cluster radii is required to obtain the desired result by FIS algorithm. The clustering of datasets is useful before the application of fuzzy rules.

The clustering of datasets helps to set the number of fuzzy rules for the estimation of rice crop variables using bistatic scatterometer data. The number of clusters is basically equal to the number of fuzzy rules. It categorizes the entire datasets into different clusters depending upon the variability of $\sigma^{\circ}$ at $\mathrm{VV}$-polarization and copolarization ratio of $\sigma^{\circ}$ with the temporal variation of the rice crop variables. The number of data clusters generated by using subtractive clustering depends upon the Euclidean distance between the cluster center and the data points, which are also known as radii of the cluster. The desired retrieval accuracy depends on the selection of the optimum value of radii. The optimization of cluster radii in the datasets is an important task to generate the optimum and desired results by FIS algorithm.

For the VWC and LAI, the number of clusters is found approximately same but slightly lesser than the number of clusters for PH. The maximum number of clusters is found for the $\mathrm{PH}$. The numerical values of VWC and LAI are found between 0 and 3. The numerical values of PH varied between 10.8 and $102 \mathrm{~cm}$ in our crop bed. The analysis based on numerical range of datasets helps to reduce the number of attempts in trial and error method for the computation of the optimum values of clusters and radii for a given FIS.

Figures 5(a)-5(c) and 6(a)-6(c) show the MF curve that defines the relation of each point in the input space mapped with the membership value (or degree of membership) between 0 and 1 at VV-polarization and copolarization for rice VWC, LAI, and PH, respectively. The input values
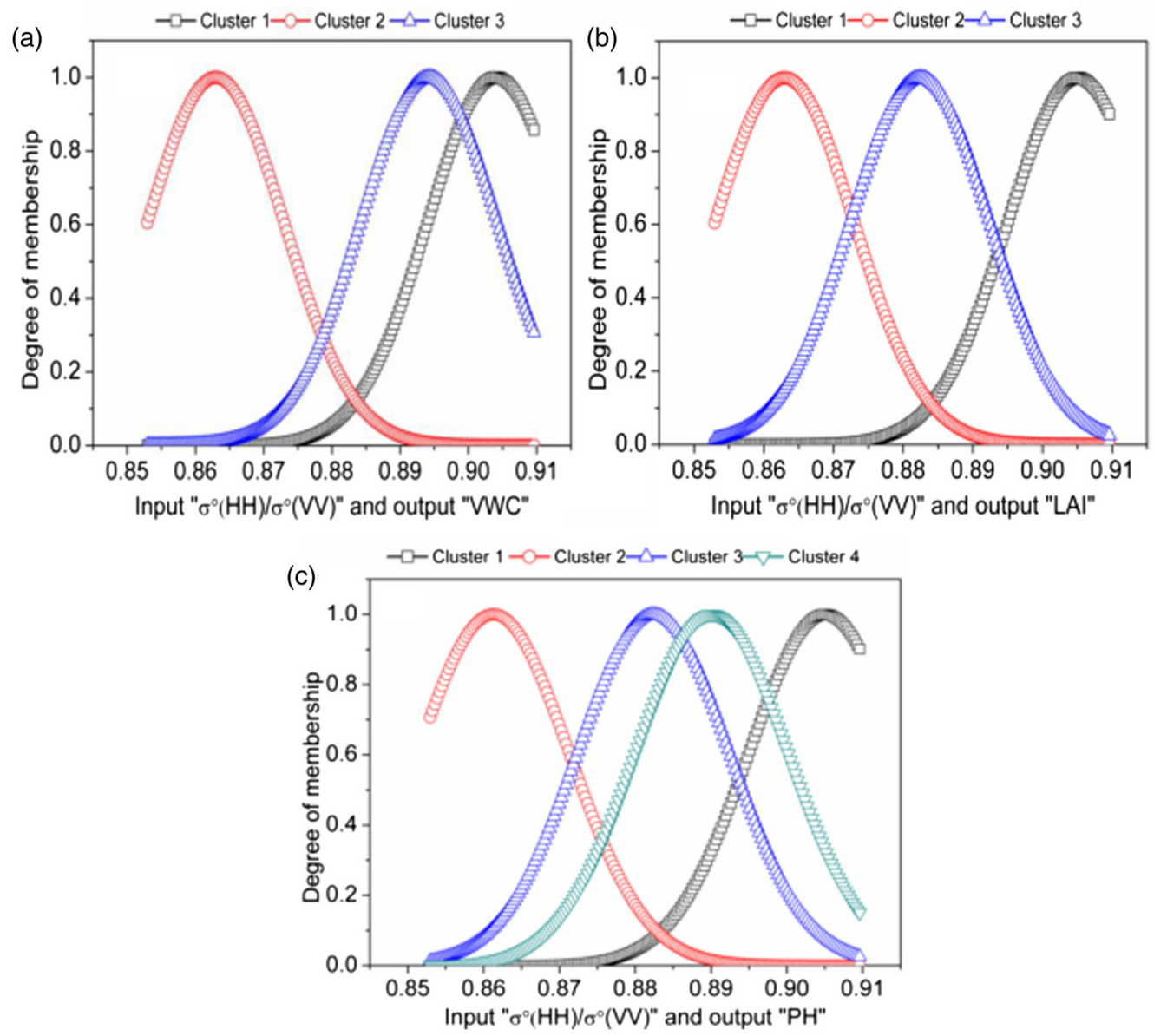

Fig. 6 MF plot at VV-polarization for (a) VWC, (b) LAI, and (c) PH. 
Table 4 Optimum parameter SVR during training of algorithms [class of SVM used: ksvm; type of SVM used: $\varepsilon$-SVR (regression); kernel function used: Gaussian radial basis].

\begin{tabular}{lcccccc}
\hline \hline $\begin{array}{l}\text { Rice crop } \\
\text { variables }\end{array}$ & $\begin{array}{c}\text { Epsilon } \\
(\varepsilon)\end{array}$ & $\begin{array}{c}\text { Cost } \\
(\mathrm{C})\end{array}$ & $\begin{array}{c}\text { Hyperparameter } \\
(\sigma)\end{array}$ & $\begin{array}{c}\text { Number of support } \\
\text { vectors }\end{array}$ & $\begin{array}{c}\text { Objective function } \\
\text { value }\end{array}$ & Polarization \\
\hline VWC & 0.10 & 5.00 & 98.02 & 50 & -78.33 & VV \\
LAl & 0.10 & 5.00 & 14.22 & 47.00 & -75.17 & VV \\
PH & 0.10 & 5.00 & 28.49 & 43.00 & -46.44 & VV \\
VWC & 0.10 & 5.00 & 14.06 & 42.00 & -118.02 & $\mathrm{HH} / \mathrm{VV}$ \\
LAl & 0.10 & 5.00 & 7.19 & 49.00 & -102.19 & $\mathrm{HH} / \mathrm{VV}$ \\
$\mathrm{PH}$ & 0.10 & 5.00 & 11.69 & 44.00 & -94.25 & $\mathrm{HH} / \mathrm{VV}$ \\
\hline \hline
\end{tabular}

are coded in the form of MF. The Gaussian MF is used to establish the fuzzy rules between each cluster in the present study.

The epsilon support vector regression ( $\varepsilon$-SVR) approach is also used for the estimation of rice crop variables using VV polarized $\sigma^{\circ}$ and copolarized ratio of bistatic scattering coefficients. The estimation accuracy by SVR depends on the selection of the optimum values of cost $(C)$, epsilon $(\varepsilon)$, and the kernel parameters.

The trial-and-error approach is used for the selection of optimum and best parameters of the SVR. The error between estimated and observed values of rice crop variables is continuously monitored during the training of SVR. The optimum value of hyperparameter $(\sigma)$ of the Gaussian radial basis kernel function is selected using the heuristics method.

Table 4 shows the optimum values of hyperparameters, number of support vectors, and values of objective function at $\varepsilon=0.1$ and $C=5$ during the training of SVR for the estimation of rice crop variables using $\mathrm{VV}$ and copolarized ratio of $\sigma^{\circ}$.

\section{Results and Discussion}

\subsection{Time Series Analysis of Bistatic Scattering Coefficients and Rice Crop Variables}

Utmost care is taken to avoid the possibility of variability in the measurement of each of the rice crop variables. However, the sources of possibility for the variability in the measurement of rice crop variables may be due to the counting of clusters $/ \mathrm{m}^{2}$, measurements of weights before and after drying the samples, and sunlight condition.

Figures 7(a)-7(c) show a temporal trend of the rice crop variables as a function of days after transplanting. The VWC is found to increase up to the reproductive stage and the middle of the repining stage, and then after started decreasing. The temporal trend of LAI is found to increase rapidly during the vegetative stage and then after increases slowly at the middle of the ripening stage and finally started decreasing. The temporal behavior of rice $\mathrm{PH}$ is found increasing rapidly during the vegetative stage and then after is found to increase slowly.

Figures 8 and 9 show the temporal signature of $\sigma^{\circ}$ in the incidence angle range of 20 deg to $70 \mathrm{deg}$ at steps of $5 \mathrm{deg}$ for $\mathrm{HH}$ - and $\mathrm{VV}$-polarization as a function of day of observations made after transplanting. Figure 10 shows the temporal trend of copolarized ratio of $\sigma^{\circ}$. Each point on the graph shows the average of three independent measurements of $\sigma^{\circ}$ by repeating the measurements. The temporal trend of $\sigma^{\circ}$ was found decreasing at a certain point and then slightly increases at all the incidence angles for $\mathrm{HH}$ - and VV-polarizations. The $\sigma^{\circ}$ shows decreasing behavior with increasing rice crop growth variables. The saturation in the temporal trend of $\sigma^{\circ}$ is not found at any growth stage of rice crop grown in our crop bed. The $\sigma^{\circ}$ is found sensitive even for a small change in the rice crop variables during its various growth stages. ${ }^{41,42}$ The larger dynamic ranges of $\sigma^{\circ}$ are found to be 23 and $27 \mathrm{~dB}$ for $\mathrm{HH}-$ and $\mathrm{VV}$-polarization at 30-deg 

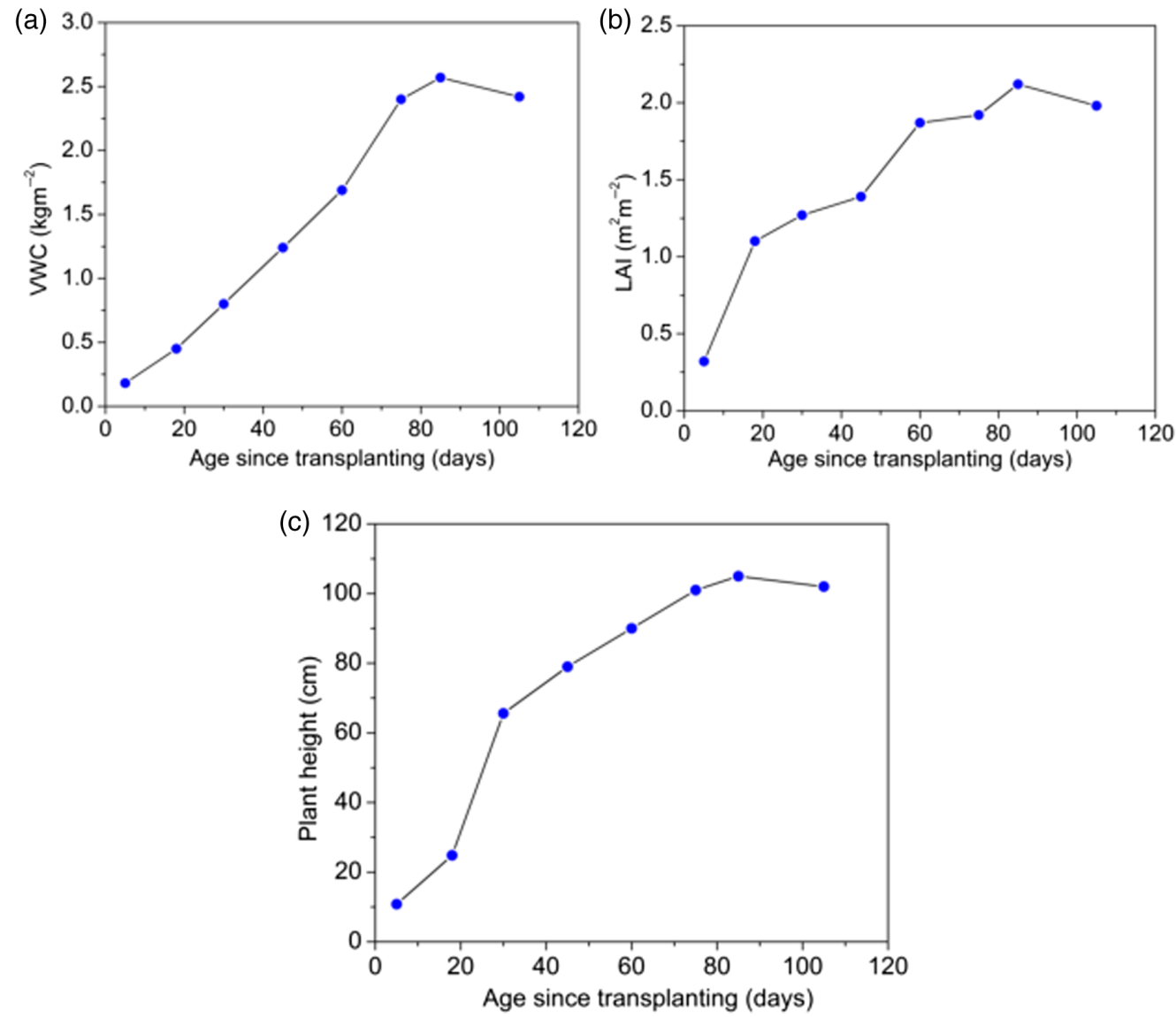

Fig. 7 Temporal variation of rice crop variables for (a) VWC, (b) LAl, and (c) PH.

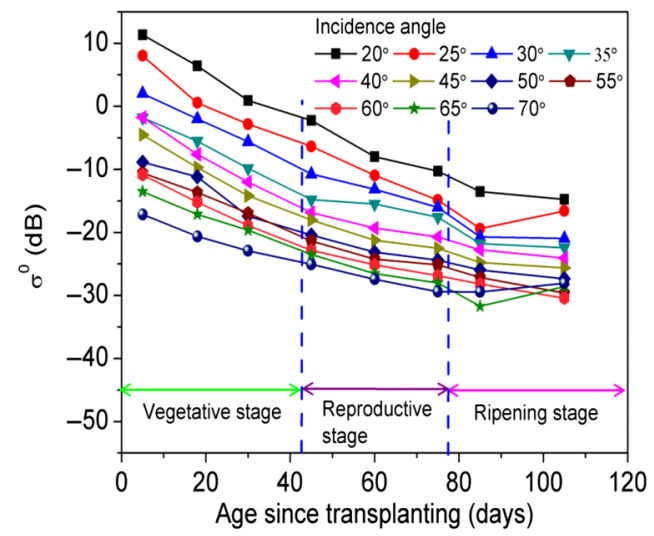

Fig. 8 Temporal variation of bistatic scattering coefficient at different incidence angles for $\mathrm{HH}$-polarization.

incidence angle, respectively. At the vegetative stage, the $\sigma^{\circ}$ of the rice crop in the specular direction is dominated by the reflection of the coherent component due to water underneath.

As the crop grows, the leaves become dense, it blocks the random scattering by water underneath and contributes the random scattering by the stems and leaves of the rice crop during the reproductive stage. Therefore, the $\sigma^{\circ}$ decreases during the reproductive stage. During the reproductive stage, the contribution of the coherent component of the microwave in the specular direction decreases. At the ripening stage of rice crop, the increasing trend of $\sigma^{\circ}$ is found. The trend of the copolarization ratio is found to be approximate flatter pattern after 30 days of transplanting. As the crop grows, the dominance of random scattering is found to increase. 


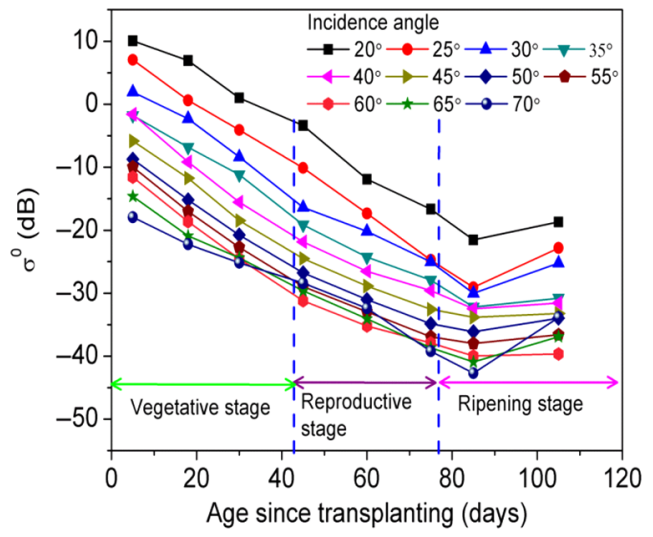

Fig. 9 Temporal variation of bistatic scattering coefficient at different incidence angles for VV-polarization.

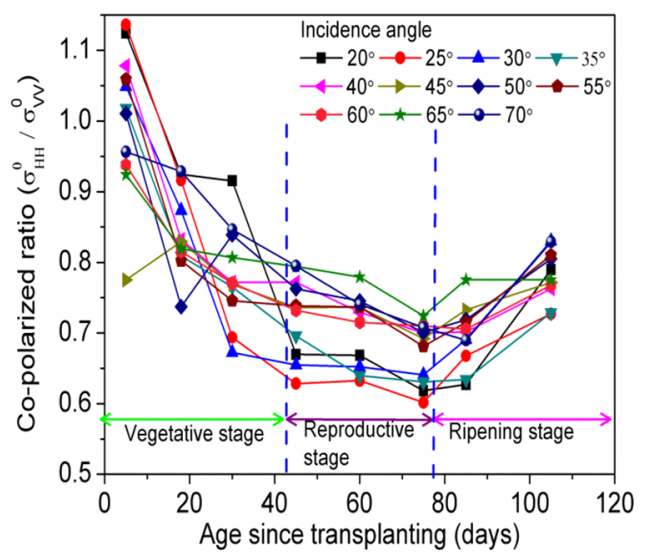

Fig. 10 Temporal variation of the polarization ratio ( $\mathrm{HH}$ pol./VV pol.) at different incidence angles.

\subsection{Estimation of Rice Crop Variables}

The performance of different machine learning algorithms (FIS and SVR) along with GLM model is evaluated by comparing the values of some performance indices [RMSE, bias (\%), and $R^{2}$ ] during training and testing of machine learning algorithms and GLM using the six different datasets described in Sec. 2.3. The values of performance indices are computed between estimated and observed rice crop variables.

Figures 11(a)-11(c) depict the scatter plot with 1:1 line between observed and estimated values of rice crop variables by FIS using training and testing datasets. Figures 12(a)-12(c) depict the scatter plot with 1:1 line between observed and estimated values of rice crop variables by SVR using training and testing datasets. The estimation accuracy by SVR depends on the selection of the optimum values of cost $(C)$, epsilon $(\varepsilon)$, and the kernel parameters. Figures 13(a)-13(c) depict the scatter plot with 1:1 line between observed and estimated values of rice crop variables by GLM using training and testing datasets, respectively. Tables 5-7 depict the values of performance indices during training and testing of the FIS, SVR, and GLM, respectively, between the observed and estimated values of rice crop variables using VV-polarized $\sigma^{\circ}$ and the copolarized ratio of $\sigma^{\circ}$. The performance indices analysis during the testing of the developed model shows the relatively higher values of $R^{2}$ by SVR model among the three different models. The $R^{2}$ values obtained by SVR are found to be $0.986,0961$, and 0.988 for VWC, LAI, and PH, respectively, at copolarized ratio of $\sigma^{\circ}$.

The performance of FIS and SVR algorithms for the estimation of rice crop variables during training and testing using dataset (VV-polarized $\sigma^{\circ}$ and the copolarized ratio of $\sigma^{\circ}$ ) is evaluated by comparing the values of performance indices for all three rice crop variables. The values of 
Gupta et al.: Robust machine learning techniques for rice crop variables estimation...
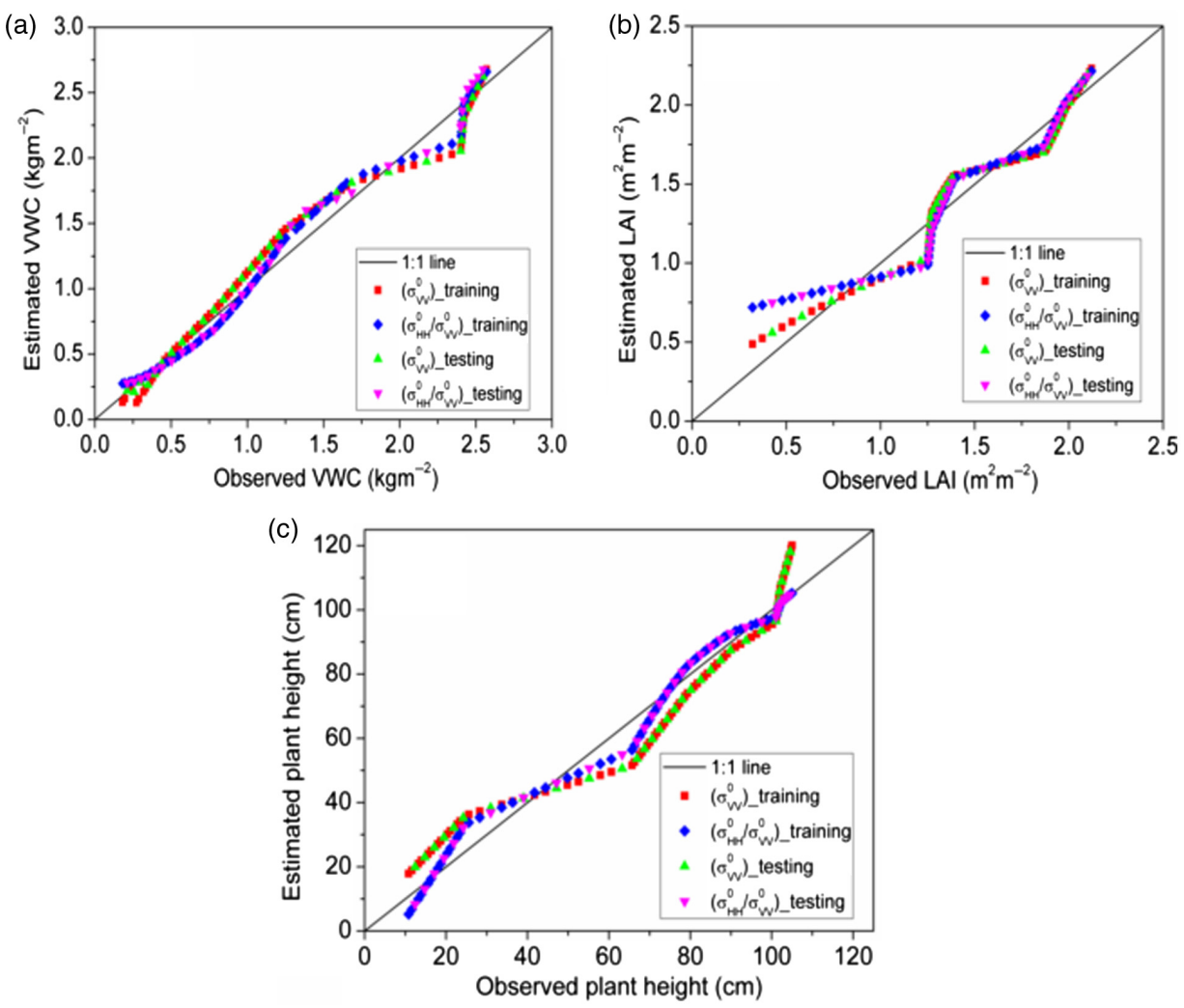

Fig. 11 (a-c) Relative scatter plots with 1:1 line between FIS estimated and observed rice crop variables: (a) VWC, (b) $\mathrm{LAl}$, and (c) PH using training and testing datasets for VV-polarized $\sigma^{\circ}$ and copolarized ratio of $\sigma^{\circ}$.
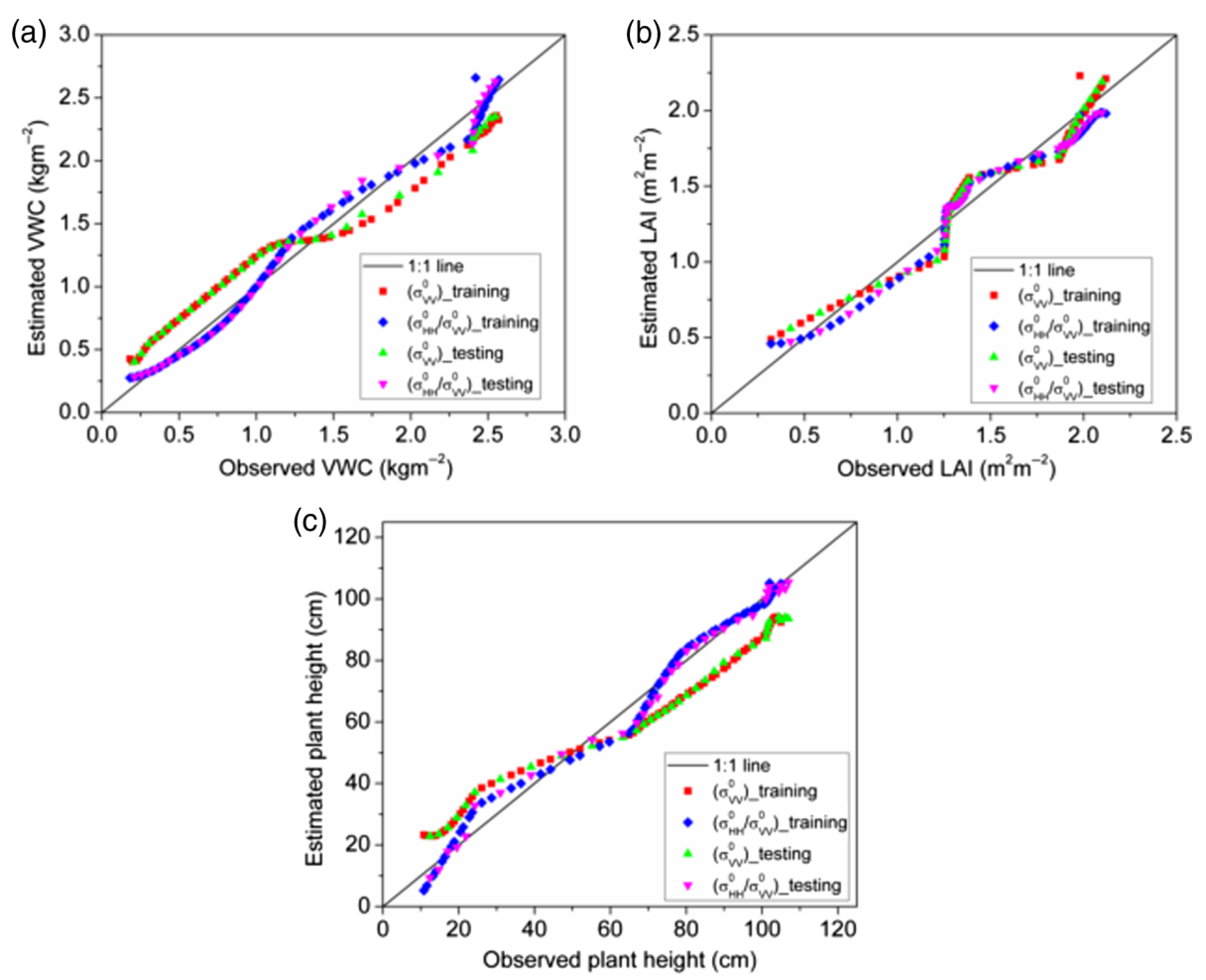

Fig. 12 (a-c) Relative scatter plots with 1:1 line between SVR estimated and observed rice crop variables: (a) VWC, (b) LAl, and (c) PH using training and validation datasets for VV-polarized $\sigma^{\circ}$ and copolarized ratio of $\sigma^{\circ}$. 

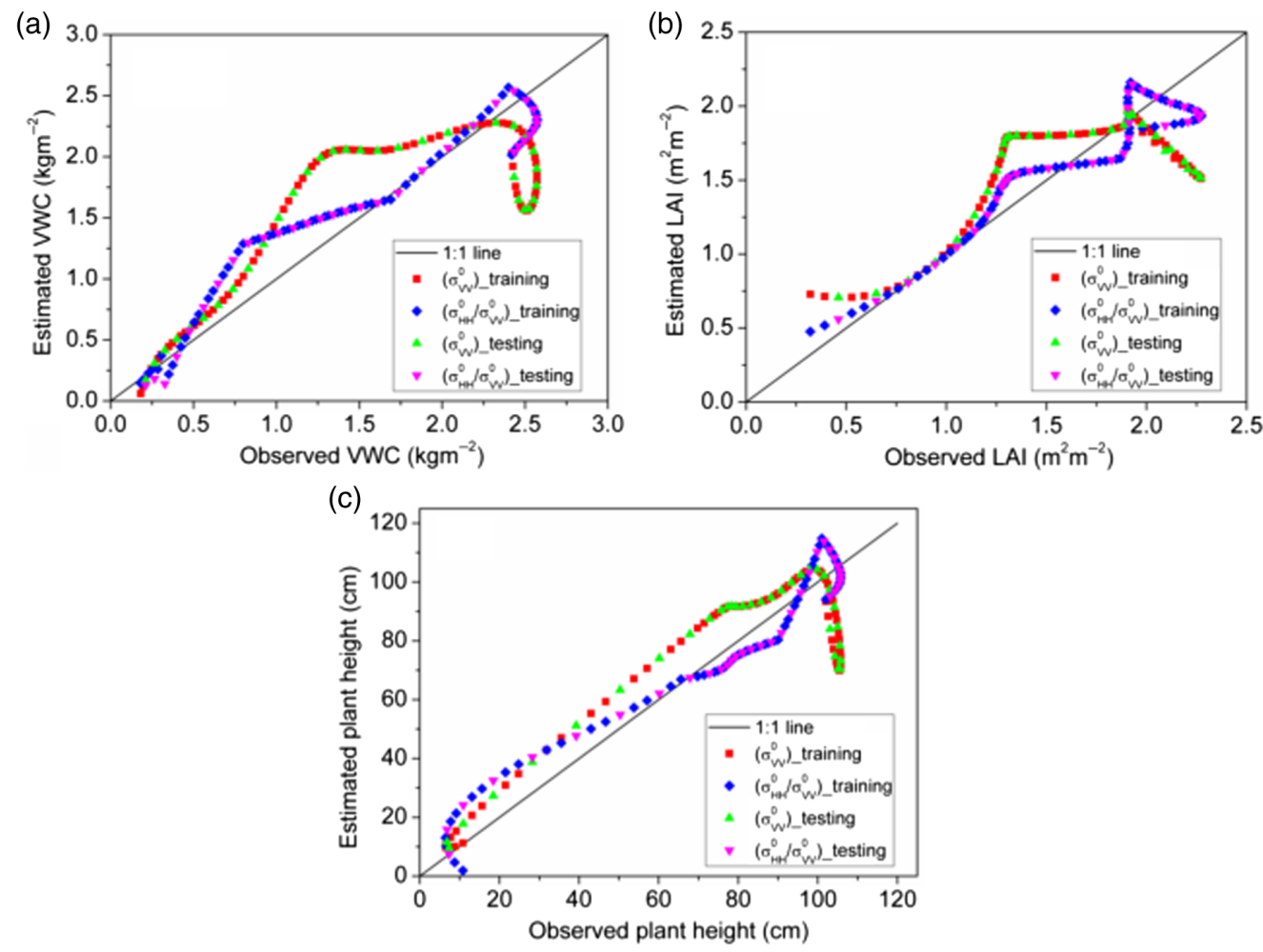

Fig. $13(a-c)$ Relative scatter plots with 1:1 line between GLM estimated and observed rice crop variables: (a) VWC, (b) LAl, and (c) $\mathrm{PH}$ using training and validation datasets for VV-polarized $\sigma^{\circ}$ and copolarized ratio of $\sigma^{\circ}$.

Table 5 Statistical performance indices during training and testing using FIS.

\begin{tabular}{|c|c|c|c|c|c|c|}
\hline \multirow[b]{2}{*}{ Performance parameter } & \multicolumn{3}{|c|}{ VV } & \multicolumn{3}{|c|}{$\mathrm{HH} / \mathrm{VV}$} \\
\hline & VWC & LAI & $\mathrm{PH}$ & VWC & LAI & $\mathrm{PH}$ \\
\hline & \multicolumn{6}{|c|}{ Training of algorithm } \\
\hline RMSE & 0.133 & 0.104 & 8.059 & 0.096 & 0.129 & 3.700 \\
\hline Bias (\%) & 1.093 & 0.213 & -0.021 & 0.277 & 0.213 & -0.021 \\
\hline \multirow[t]{2}{*}{$R^{2}$} & 0.973 & 0.947 & 0.932 & 0.985 & 0.920 & 0.985 \\
\hline & \multicolumn{6}{|c|}{ Testing of algorithm } \\
\hline RMSE & 0.133 & 0.103 & 7.901 & 0.095 & 0.120 & 3.676 \\
\hline Bias (\%) & 1.332 & -0.101 & -0.510 & 1.175 & -0.329 & 0.102 \\
\hline$R^{2}$ & 0.972 & 0.943 & 0.932 & 0.986 & 0.923 & 0.985 \\
\hline
\end{tabular}

estimated and observed rice crop variables are found to be very close during training and testing by these machine learning algorithms. The performance of GLM, for the estimation of rice crop variable by $\mathrm{VV}$-polarized $\sigma^{\circ}$ and the copolarized ratio of $\sigma^{\circ}$, is found equally good during the training and testing datasets. The estimation of VWC is found to be better than the LAI and PH by SVR, FIS, and GLM using VV-polarized $\sigma^{\circ}$, while the estimation of PH is found better than VWC and LAI using a copolarized ratio of $\sigma^{\circ}$ during training and testing of these machine learning algorithm and GLM. 
Gupta et al.: Robust machine learning techniques for rice crop variables estimation...

Table 6 Statistical performance indices during training and testing of SVR.

\begin{tabular}{|c|c|c|c|c|c|c|}
\hline \multirow[b]{2}{*}{ Performance parameter } & \multicolumn{3}{|c|}{ VV } & \multicolumn{3}{|c|}{$\mathrm{HH} / \mathrm{VV}$} \\
\hline & VWC & LAI & $\mathrm{PH}$ & VWC & LAI & $\mathrm{PH}$ \\
\hline & \multicolumn{6}{|c|}{ Training of algorithm } \\
\hline RMSE & 0.221 & 0.113 & 10.315 & 0.090 & 0.099 & 3.491 \\
\hline Bias (\%) & 3.319 & 0.040 & -7.207 & 0.002 & -1.944 & -1.325 \\
\hline \multirow[t]{2}{*}{$R^{2}$} & 0.983 & 0.939 & 0.979 & 0.987 & 0.961 & 0.988 \\
\hline & \multicolumn{6}{|c|}{ Testing of algorithm } \\
\hline RMSE & 0.210 & 0.103 & 10.516 & 0.988 & 0.092 & 3.387 \\
\hline Bias (\%) & 3.773 & -0.101 & -7.724 & 0.059 & -1.804 & -0.502 \\
\hline$R^{2}$ & 0.986 & 0.943 & 0.979 & 0.986 & 0.961 & 0.988 \\
\hline
\end{tabular}

Table 7 Statistical performance indices during training and testing of GLM.

\begin{tabular}{|c|c|c|c|c|c|c|}
\hline \multirow[b]{2}{*}{ Performance parameter } & \multicolumn{3}{|c|}{ VV } & \multicolumn{3}{|c|}{$\mathrm{HH} / \mathrm{VV}$} \\
\hline & VWC & LAI & $\mathrm{PH}$ & VWC & LAI & $\mathrm{PH}$ \\
\hline & \multicolumn{6}{|c|}{ Training of algorithm } \\
\hline RMSE & 0.505 & 0.358 & 15.823 & 0.249 & 0.168 & 7.207 \\
\hline Bias (\%) & $3.81 \times 10^{-5}$ & $2.77 \times 10^{-5}$ & $3.86 \times 10^{-7}$ & 2.142 & -0.475 & 0.064 \\
\hline \multirow[t]{2}{*}{$R^{2}$} & 0.752 & 0.612 & 0.730 & 0.823 & 0.800 & 0.851 \\
\hline & \multicolumn{6}{|c|}{ Testing of algorithm } \\
\hline RMSE & 0.511 & 0.359 & 16.048 & 0.248 & 0.169 & 7.097 \\
\hline Bias (\%) & 0.480 & -0.304 & 0.130 & 1.773 & -0.574 & 0.952 \\
\hline$R^{2}$ & 0.734 & 0.570 & 0.711 & 0.817 & 0.791 & 0.849 \\
\hline
\end{tabular}

The aforementioned analysis and comparison of performance indices indicate that the FIS and SVR algorithms may provide better results than GLM for the estimation of rice crop variables using VV-polarized $\sigma^{\circ}$ and the copolarized ratio of $\sigma^{\circ}$. However, the performance of SVR is found superior to the FIS and GLM during the training and testing of these algorithms. The estimated values of LAI and $\mathrm{PH}$ are also found in good agreement with the observed values using VV-polarized $\sigma^{\circ}$ and the copolarized ratio of $\sigma^{\circ}$ dataset by machine learning algorithm and GLM. The estimation of rice crop variables is found more accurate using a copolarized ratio of $\sigma^{\circ}$ dataset than VV-polarized $\sigma^{\circ}$ dataset by all the machine learning algorithm and GLM used in the present study.

\section{Conclusion}

The decreasing trend of $\sigma^{\circ}$ with the age of rice crop is observed in the angular range of the incidence angle $20 \mathrm{deg}$ to $70 \mathrm{deg}$ at steps of $5 \mathrm{deg}$ at HH- and VV-polarization for X-band during vegetative and reproductive stages, whereas increasing trend is observed during ripening stage. The computed copolarization ratio of $\sigma^{\circ}$ showed the decreasing trend with the age of rice crop for the entire range of incidence angles. The maximum values of $R^{2}$ are found at 30-deg and 35-deg incidence angles for both like polarization and copolarized ratio of $\sigma^{\circ}$, respectively. However, 
the VV-polarized $\sigma^{\circ}$ is found more sensitive in comparison to $\mathrm{HH}$-polarized $\sigma^{\circ}$ with the rice crop variables. The copolarized ratio of $\sigma^{\circ}$ is found to be more sensitive with crop growth variables in comparison to both like polarizations. The FIS and SVR provide better results than GLM for the estimation of rice crop variables using VV-polarized $\sigma^{\circ}$ and copolarization ratio of $\sigma^{\circ}$. The approach of copolarized ratio provides a more accurate estimation of rice crop variables by FIS, SVR, and GLM algorithms in comparison to VV-polarized $\sigma^{\circ}$. However, the performance of SVR is found to be more accurate than the FIS and GLM algorithms. The estimation of VWC is found more accurate than the other rice crop variables by all three different algorithms. Nevertheless, the estimated values of LAI and PH are also found to be in agreement with the observed values. The present study may help to determine the optimum incidence angle, polarization, and suitable machine learning algorithm for the estimation of rice crop variables for effective monitoring of rice crop growth using bistatic scatterometer system on-board satellite.

\section{References}

1. Y. Kim et al., "Radar vegetation index for estimating the vegetation water content of rice and soybean," IEEE Geosci. Remote Sens. Lett. 9(4), 564-568 (2012).

2. T. Kurosu et al., "Monitoring of rice crop growth from space using the ERS-1 C-band SAR," IEEE Trans. Geosci. Remote Sens. 33(4), 1092-1096 (1995).

3. T. L. Toan et al., "Rice crop mapping and monitoring using ERS-1 data based on experiment and modeling results," IEEE Trans. Geosci. Remote Sens. 35(1), 41-56 (1997).

4. W. Koppe et al. "Rice monitoring with multi-temporal and dual-polarimetric TerraSAR-X data," Int. J. Appl. Earth Obs. Geoinf. 21, 568-576 (2013).

5. Y. Shao et al., "Rice monitoring and production estimation using multitemporal RADARSAT," Remote Sens. Environ. 76(3), 310-325 (2001).

6. Y. Inoue et al., "Season-long daily measurements of multifrequency (Ka, Ku, X, C, and L) and full-polarization backscatter signatures over paddy rice field and their relationship with biological variables," Remote Sens. Environ. 81(2), 194-204 (2002).

7. Y. Oh et al., "Polarimetric backscattering coefficients of flooded rice fields at L-and C-bands: measurements, modeling, and data analysis," IEEE Trans. Geosci. Remote Sens. 47(8), 2714-2721 (2009).

8. Y. Kim et al., "Continuous monitoring of rice growth with a stable ground-based scatterometer system," IEEE Geosci. Remote Sens. Lett. 10(4), 831-835 (2013).

9. X. Chunliang et al., "Measuring the microwave backscattering coefficient of paddy rice using FM-CW ground-based scatterometer," in Int. Workshop on Education Technology and Training and Int. Workshop on Geoscience and Remote Sensing (2008).

10. Y. Kim et al., "Radar backscattering measurement of a paddy rice field using multifrequency (L, C and $\mathrm{X}$ ) and full-polarization," in Int. IEEE Geoscience and Remote Sensing Symp. (2008).

11. K. SooBum et al., "Radar backscattering measurements of rice crop using X-band scatterometer," IEEE Trans. Geosci. Remote Sens. 38(3), 1467-1471 (2000).

12. P. Liang et al., "Radiative transfer model for microwave bistatic scattering from forest canopies," IEEE Trans. Geosci. Remote Sens. 43(11), 2470-2483 (2005).

13. E. Erten et al., "Polarization impact in TanDEM-X data over vertical-oriented vegetation: the paddy-rice case study," IEEE Geosci. Remote Sens. Lett. 12(7), 1501-1505 (2015).

14. C. Rossi and E. Erten, "Paddy-rice monitoring using TanDEM-X," IEEE Trans. Geosci. Remote Sens. 53(2), 900-910 (2015).

15. Z. Yang et al., "Auto-tuning method of fuzzy PID controller parameter based on self-learning system," in 11th IEEE Int. Conf. on Fuzzy Systems and Knowledge Discovery (2014).

16. S.-W. Lin et al., "Particle swarm optimization for parameter determination and feature selection of support vector machines," Expert Syst. Appl. 35(4), 1817-1824 (2008).

17. C.-L. Huang and C.-J. Wang, "A GA-based feature selection and parameters optimization for support vector machines," Expert Syst. Appl. 31(2), 231-240 (2006).

18. D. Tuia et al., "Multioutput support vector regression for remote sensing biophysical parameter estimation," IEEE Geosci. Remote Sens. Lett. 8(4), 804-808 (2011). 
19. R. Prasad and D. Singh, "A radial basis function approach to retrieve soil moisture and crop variables from X-band scatterometer observations," Prog. Electromagn. Res. B 12, 201-217 (2009).

20. D. K. Gupta et al., "Bistatic measurements for the estimation of rice crop variables using artificial neural network," Adv. Space Res. 55(6), 1613-1623 (2015).

21. D. Frate et al., "Retrieving soil moisture and agricultural variables by microwave radiometry using neural networks," Remote Sens. Environ. 84(2), 174-183 (2003).

22. G. Camps-Valls et al., "Robust support vector regression for biophysical variable estimation from remotely sensed images," IEEE Geosci. Remote Sens. Lett. 3(3), 339-343 (2006).

23. A. Pandey et al., "Crop parameters estimation by fuzzy inference system using X-band scatterometer data," Adv. Space Res. 51(5), 905-911 (2013).

24. M. Jia et al., "Rice biomass retrieval from multitemporal ground-based scatterometer data and RADARSAT-2 images using neural networks," J. Appl. Remote Sens. 7(1), 073509 (2013).

25. F. T. Ulaby et al., Microwave Radar and Radiometric Remote Sensing, University of Michigan Press, Ann Arbor, Michigan (2014).

26. F. T. Ulaby et al., Microwave Remote Sensing Active and Passive-Volume II: Radar Remote Sensing and Surface Scattering and Emission Theory, Addison-Wesley, Reading, Massachusetts (1982).

27. S. Cohen et al., "Canopy transmittance inversion using a line quantum probe for a row crop," Agric. For. Meteorol. 86(3), 225-234 (1997).

28. J. M. Kovacs et al., "Evaluating the condition of a mangrove forest of the Mexican Pacific based on an estimated leaf area index mapping approach," Environ. Monit. Assess. 157(1-4), 137-149 (2009).

29. S. Delalieux et al., "A near-infrared narrow-waveband ratio to determine leaf area index in orchards," Remote Sens. Environ. 112(10), 3762-3772 (2008).

30. A. Priyono et al., "Generation of fuzzy rules with subtractive clustering," J. Teknol. 43(1), 143-153 (2012).

31. K. S. Ajil et al., "A new technique for temperature and humidity profile retrieval from infrared-sounder observations using the adaptive neuro-fuzzy inference system," IEEE Trans. Geosci. Remote Sens. 48(4), 1650-1659 (2010).

32. C.-J. Lin, "An efficient immune-based symbiotic particle swarm optimization learning algorithm for TSK-type neuro-fuzzy networks design," Fuzzy Sets Syst. 159(21), 2890-2909 (2008).

33. T. Takagi and M. Sugeno, "Fuzzy identification of systems and its applications to modeling and control," IEEE Trans. Syst. Man Cybern. SMC-15(1), 116-132 (1985).

34. M. Sugeno and G. T. Kang, "Structure identification of fuzzy model," Fuzzy Sets Syst. 28(1), 15-33 (1988).

35. S. L. Chiu, "Fuzzy model identification based on cluster estimation," J. Intell. Fuzzy Syst. 2(3), 267-278 (1994).

36. V. Vapnik et al., "Support vector method for function approximation, regression estimation and signal processing," in Advances in Neural Information Processing Systems (1997).

37. V. Anandhi and R. M. Chezian, "Support vector regression to forecast the demand and supply of pulpwood," Int. J. Future Comput. Commun. 2(3), 266-269 (2013).

38. C.-W. Hsu and C.-J. Lin, "A simple decomposition method for support vector machines," Mach. Learn. 46(1-3), 291-314 (2002).

39. J. K. Lindsey, Applying Generalized Linear Models, Springer Verlag, New York (1997).

40. P. K. Srivastava et al., "Data fusion techniques for an improved soil moisture retrieval using SMOS and WRF-NOAH land surface model," in SMOS Land Application Workshop, ESA-ESRIN, Frascati, Italy (2013).

41. P. Ferrazzoli, L. Guerriero, and D. Solimini, "Simulating bistatic scatter from surfaces covered with vegetation," J. Electromagn. Waves Appl. 14, 233-248 (2000).

42. Y.-Y. Zhang and Z.-S. Wu, "Bistatic scattering characteristics of wheat and soybean by radiative transfer model in L band and C band," Prog. Electromagn. Res. 67, 121-136 (2016).

Dileep Kumar Gupta received his BSc and MSc degrees in electronics from Kanpur University, Kanpur, India. He received his PhD degree in physics from the Institute of Technology (BHU), 
Varanasi, in 2017. He is currently working as a research associate at the Institute of Environment and Sustainable Development (BHU). His current research interest includes the development of high-resolution soil moisture products by disaggregation of SMAP, SMOS, and Scatsat-1 satellite data for operational use.

Rajendra Prasad received his BSc and MSc degrees in physics from Banaras Hindu University, Varanasi, India. He received his PhD degree from the Institute of Technology (BHU), Varanasi, in 1998. He is currently a professor of physics at Indian Institute of Technology (BHU). His current research interests include retrieval of soil moisture and monitoring of crops by estimating the crop variables at various growth stages using microwave remote sensing and artificial intelligence techniques.

Pradeep Kumar received his PhD degree from the Department of Physics, Indian Institute of Technology (BHU), Varanasi, India. He is currently working as SERB-National Post-Doctoral Fellow in the Department of Physics, Institute of Science, Banaras Hindu University, Varanasi, India. His research interests include monitoring of different crop growth/yield and soil moisture retrieval using multisensor satellite data. Currently, he is working on the impact of atmospheric aerosols and air pollutants on agricultural crop growth and yield.

Prashant K. Srivastava received his $\mathrm{PhD}$ degree from the University of Bristol, United Kingdom. Currently, he is working as an assistant professor at Institute of Environment and Sustainable Development, Banaras Hindu University, India. He has worked as a research scientist, Hydrological Sciences, NASA GSFC, Greenbelt, Maryland, United States. He has published more than 100 research articles in reputed journals, conference proceedings, book chapters, etc. He is an associate editor in many reputed journals.

Tanvir Islam received his $\mathrm{PhD}$ degree from the University of Bristol, Bristol, United Kingdom, in 2012. He is presently with the NASA JPL, who specializes in remote sensing observations. Currently, he is engaged with the development of advanced microwave calibration and retrieval algorithms for NASA's Earth observing missions. His primary research interests include microwave remote sensing, radiometer calibration, retrieval algorithms, radiative transfer theory, mesoscale modeling, cloud and precipitation system, and artificial intelligence in geosciences. 